Supplement of Atmos. Chem. Phys. Discuss., 15, 34981-35034, 2015

http://www.atmos-chem-phys-discuss.net/15/34981/2015/

doi:10.5194/acpd-15-34981-2015-supplement

(C) Author(s) 2015. CC Attribution 3.0 License.

(c) (i)

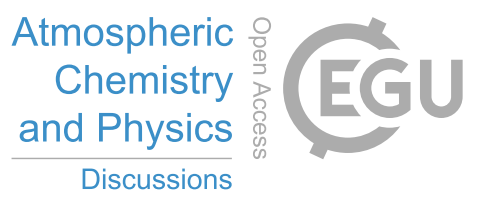

Supplement of

\title{
Phase, composition and growth mechanism for secondary organic aerosol from the ozonolysis of $\alpha$-cedrene
}

\author{
Y. Zhao et al. \\ Correspondence to: B. J. Finlayson-Pitts (bjfinlay@uci.edu)
}

The copyright of individual parts of the supplement might differ from the CC-BY 3.0 licence. 


\section{Structure identification for $\mathbf{P 2}$ products}

Theoretical studies of oligomer formation from the oxidation of monoterpenes (e.g., $\alpha$-pinene) have shown that the formation of oligomers such as aldol condensation products,

peroxyhemiacetals, and non-covalently bound dicarboxylic acid cluster is thermodynamically favorable in the gas or condensed phases (Sloth et al., 2004; Claeys et al., 2009; DePalma et al., 2013), whereas formation of hemiacetal, anhydride, di( $\alpha$-hydroxy) ether, and ester (via acidcatalyzed esterification) is not favorable in both phases (DePalma et al., 2013). A recent study has suggested that gas phase reactions involving stabilized Criegee intermediates (SCI) may be an alternative pathway for ester formation during ozonolysis, although the detailed mechanism is currently unknown (Kristensen et al., 2014). Consistently, a number of experimental and field studies have found that aldol condensation products, peroxyhemiacetals, and esters are the major oligomers detected in the SOA formed from monoterpene ozonolysis (Hoffmann et al., 1998; Tolocka et al., 2004; Muller et al., 2008, 2009; Heaton et al., 2009; Hallquist et al., 2009; Gao et al., 2010; Yasmeen et al., 2010; Hall and Johnston, 2012; Kristensen et al., 2013, 2014; Witkowski and Gierczak, 2014).

In this study, all of the potential structures including aldol condensation products, peroxyhemiacetals, esters, and non-covalently bound carboxylic clusters for the P2 products corresponding to the sodiated ions at $m / z, 481,497,511,513,527$, and 543 are examined in light of ESI-MS ${ }^{2}$ and accurate mass measurements. The structures that match both $\mathrm{MS}^{2}$ spectra (Fig. $\mathrm{S} 10)$ and elemental formulas of the $\mathrm{P} 2$ products are considered as the likely structures for these products and are given in Figs. 10 and S10. The fragmentation pathways of these structures (i.e., aldol condensation products, peroxyhemiacetals, and esters as identified below) are in general consistent with those reported in the previous studies (Tolocka et al., 2004; Muller et al., 2008, 2009; Yasmeen et al., 2010; Hall and Johnston, 2012; Witkowski and Gierczak, 2014), where

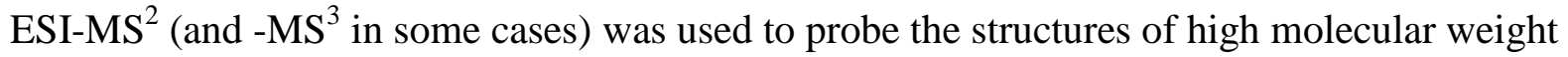
products in, for example, monoterpene SOA.

$m / z$ 481. The proposed structure (Figs. $10 \mathrm{a}$ and S10a, P2-481) is an aldol condensation product formed by the reaction of $\alpha$-norcedronaldehyde (P1-245) and $\alpha$-cedronaldehyde (P1-259). The cleavage of the C-C bonds of $\beta$-hydroxy ketone moiety in the structure can form fragments at $\mathrm{m} / z$ 
261 and 257 In addition, the loss of small oxygenated functional groups can form large fragments at $m / z 463,451$, and 437.

$m / z$ 497. The assigned structure (Figs. $10 \mathrm{~b}$ and $\mathrm{S} 10 \mathrm{~b}, \mathrm{P} 2-497$ ) is an aldol condensation product formed by the reaction of $\alpha$-cedralic acid (P1-261) with $\alpha$-cedronaldehyde (P1-259). The prominent fragments between $m / z 245-289$ can be formed by the cleavage of the C-C bonds of $\beta$ hydroxy ketone moiety in the structure. The formation of large fragments at $m / z 479,451$, and 437 can be explained by the dehydration, decarboxylation, and combined loss of acetaldehyde and hydroxyl group, respectively. The presence of a carboxylic acid group in this structure is consistent with the prominence of the corresponding deprotonated ion (i.e., $\mathrm{m} / \mathrm{z} 473$ ) of this product in the ESI- mass spectrum as shown in Fig. 6b, which is particularly sensitive to the carboxylic acid. Note that another aldol condensation product formed by the reaction of $\alpha$ norcedronaldehyde (P1-245) with 15-hydroxy- $\alpha$-cedronaldehyde (P1-275-1) or 10-hydroxy- $\alpha$ cedronaldehyde (P1-275-2) is also consistent with the elemental formula and $\mathrm{MS}^{2}$ spectrum of the product. However, the absence of carboxylic acid group in this structure indicates its contribution may not be important.

$m / z$ 511. Of four proposed structures (Figs. $10 \mathrm{c}$ and S10c), two are esters (P2-511-1 and P2-5112 ), with the building blocks corresponding to 15-hydroxy- $\alpha$-cedronaldehyde (P1-275-1) and $\alpha$ cedrinic acid (P1-277-1), and to $\alpha$-cedralic acid (P1-261) and 15-hydroxy- $\alpha$-cedronic acid (P1291-1). Another two structures are aldol condensation products (P2-511-3 and P2-511-4) formed by the reactions of $\alpha$-norcedronaldehyde (P1-245) with 15-oxo- $\alpha$-cedronic acid (P1-289) and $\alpha$ cedronaldehyde (P1-259) with 15-hydroxy- $\alpha$-cedronaldehyde (P1-275-1). The fragmentation of the esters would give carboxylic acid $(\mathrm{m} / \mathrm{z}, 261$ and 277) or alcohol $(\mathrm{m} / \mathrm{z}, 275$ and 291) components as the major fragments, and the aldol condensation products would mainly fragment to its precursor carbonyl components (i.e., $m / z$ 245, 259, 275 and 289). Taken together, these two structures can explain almost all of the prominent peaks in the $\mathrm{MS}^{2}$ spectrum.

$m / z$ 513. Two of the proposed structures correspond to aldol condensation products (Figs. 10d and S10d, P2-513-1 and P2-513-2) formed by the reactions of $\alpha$-norcedronaldehyde (P1-245) with 15-hydroxy- $\alpha$-cedronic acid (P1-291-1) and $\alpha$-cedralic acid (P1-261) with 10-hydroxy- $\alpha$ cedronaldehyde (P1-275-2). The fragmentation of these two structures via the cleavage of the C- 
$\mathrm{C}$ bonds in $\beta$-hydroxy ketone moiety can explain the fragments at $\mathrm{m} / \mathrm{z} 245,261,275,291$, and 305. In addition, these structures can also lose $\mathrm{H}_{2} \mathrm{O}$ (18 Da), $\mathrm{CH}_{3} \mathrm{OH}(32 \mathrm{Da}), \mathrm{HCOOH}$ (46 Da), and $\mathrm{CH}_{3} \mathrm{COOH}(60 \mathrm{Da})$, leading to the formation of larger fragments at $\mathrm{m} / \mathrm{z} 495,481,467$, and 453 , respectively.

Another two structures for this product correspond to the peroxyhemiacetals (Figs. 10d and S10d, P2-513-3 and P2-513-4) formed by the reactions of 15-hydroperoxy- $\alpha$-cedronaldehyde with $\alpha$-norcedronaldehyde (P1-245) and $\alpha$-peroxycedralic acid with $\alpha$-cedronaldehyde (P1-259). By cleaving at the $\mathrm{C}-\mathrm{O}$ or $\mathrm{O}-\mathrm{O}$ bonds of the peroxy group, the peroxyhemiacetal is able to give a fragment series with a mass interval of $16 \mathrm{Da}$. This characteristic fragmentation of both peroxyhemiacetals matches the fragment series at $\mathrm{m} / \mathrm{z} 245,261$, and 277 or at $\mathrm{m} / \mathrm{z} 259,275$, and 291 in the $\mathrm{MS}^{2}$ spectrum.

The formation of organic hydroperoxides $(\mathrm{ROOH})$ from the ozonolysis of $\alpha$-cedrene has been previously reported by Reinnig et al. (2009). Using atmospheric pressure chemical ionization mass spectrometry (APCI-MS), they detected a number of $[\mathrm{M}+\mathrm{H}]^{+}$ions in the mass spectrum of $\alpha$-cedrene SOA, the $\mathrm{MS}^{2}$ spectra of which showed a characteristic loss of $\mathrm{H}_{2} \mathrm{O}_{2}$ (34 Da), indicative of the existence of the hydroperoxy group. Among detected ROOHs, two have molecular weight (MW) consistent with $\alpha$-peroxycedralic acid (MW 254, termed PO-254) and 15-hydroperoxy- $\alpha$-cedronaldehyde (MW 268, termed PO-268), suggesting that these two ROOHs are likely formed during ozonolysis. The formation of ROOHs is not detected in this study, probably due to their decomposition during SOA sampling and analysis.

$\boldsymbol{m} / \mathbf{z}$ 527. Three structures (Figs. 10e and $\mathrm{S} 10 \mathrm{e}$ ) are proposed: two aldol condensation products (P2-527-1 and P2-527-2) formed through the reactions of $\alpha$-cedronaldehyde (P1-259) with 15hydroxy- $\alpha$-cedronic acid (P1-291) and 15-hydroxy- $\alpha$-cedronaldehyde (P1-275-1) with 10hydroxy- $\alpha$-cedronaldehyde (P1-275-2), and a peroxyhemiacetal (P2-527-3) formed via the reaction of 15-hydroperoxy- $\alpha$-cedronaldehyde (PO-268) with $\alpha$-cedronaldehyde (P1-259). The prominent fragments at $m / z 245-305$ are consistent with the expected fragmentation pathway of these three structures. The larger fragments at $m / z$ 467-509 can be explained by the loss of the carboxylic, aldehyde, hydroxyl, and methylhydroxyl groups in these structures. 
$m / z$ 543. This product may have contributions from four different structures (Figs. 10f and S10f): two aldol condensation products (P2-543-1 and P2-543-2) formed from the reactions of 10hydroxy- $\alpha$-cedronaldehyde (P1-275-2) with 15-hydroxy- $\alpha$-cedronic acid (P1-291) and $\alpha$ cedronaldehyde (P1-259) with 7, 15-dihydroxy- $\alpha$-cedronic acid (P1-307-1), and two peroxyhemiacetals from the reactions of 15-hydroperoxy- $\alpha$-cedronaldehyde (PO-268) with15hydroxy- $\alpha$-cedronaldehyde (P1-275-1) and 15-hydroxy- $\alpha$-peroxycedronic acid (MW 284, termed PO-284) with $\alpha$-cedronaldehyde (P1-259). The fragments in the $\mathrm{MS}^{2}$ spectrum are in line with the most likely fragmentation pathways of the proposed structures. Again, the formation of $\mathrm{ROOH}$, with MW the same as 15-hydroxy- $\alpha$-peroxycedronic acid (PO-284), has been observed in $\alpha$-cedrene/ $\mathrm{O}_{3}$ SOA by Reinnig and coworkers (Reinnig et al., 2009). 

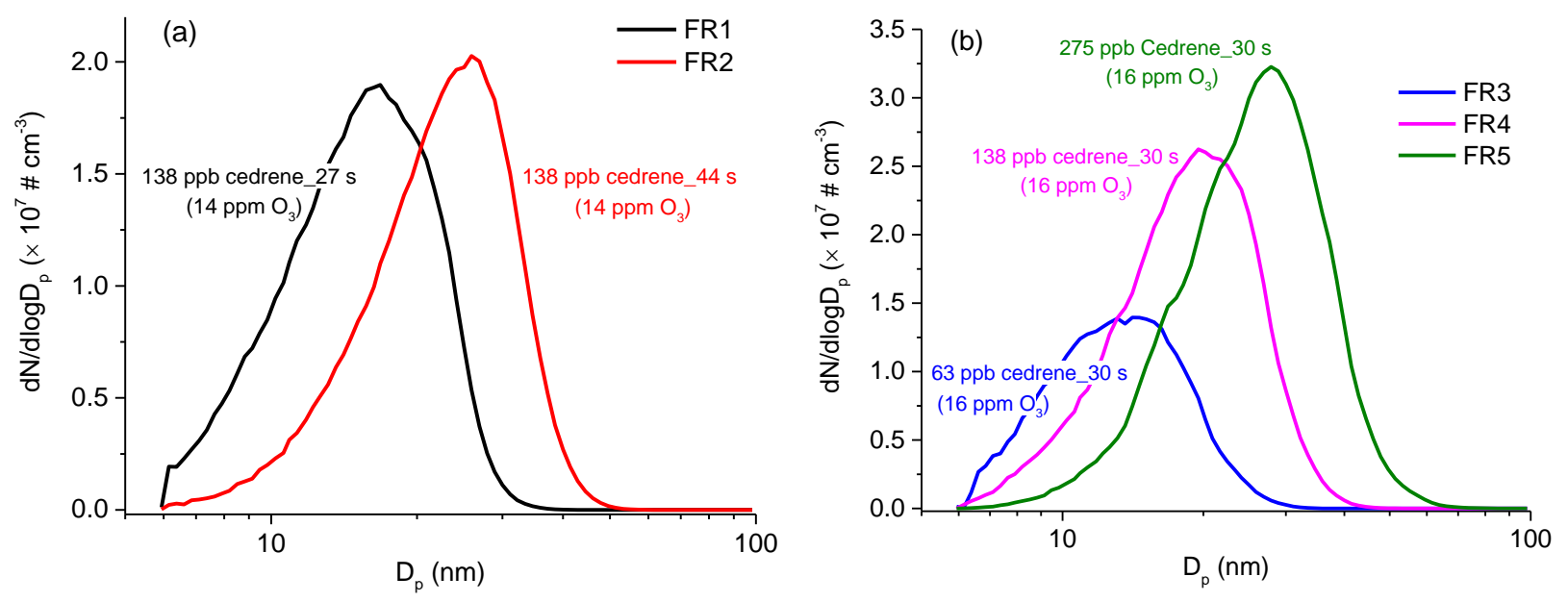

Figure S1 The size distributions of SOA formed from ozonolysis of $\alpha$-cedrene in the flow reactor under different conditions. (a) Experiments FR1- FR2. (b) Experiments FR3- FR5.

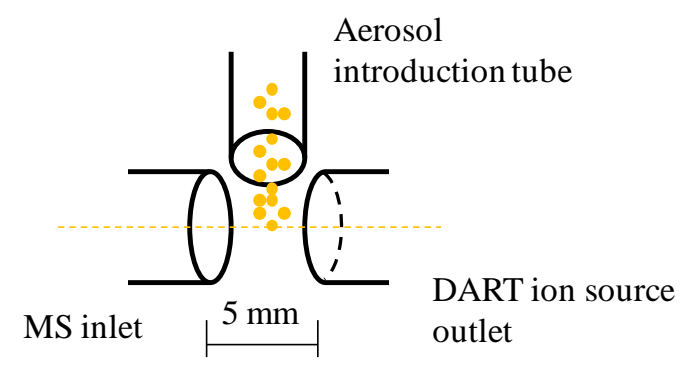

Figure S2 The configuration of the DART ion source interfaced to the MS.

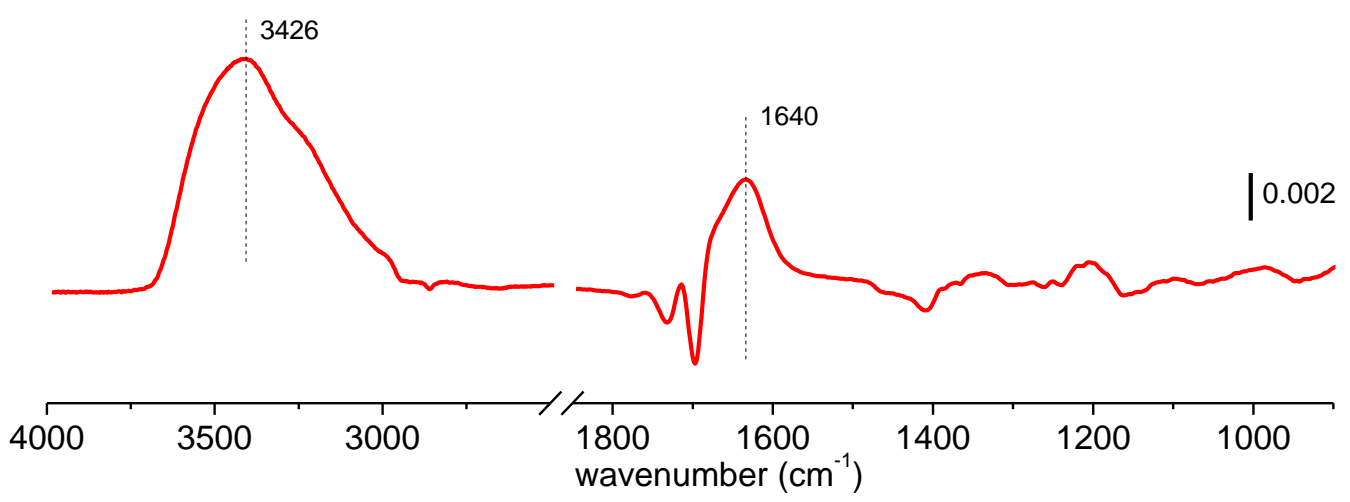

Figure S3 Difference spectrum of SOA after exposure to water vapor at $89 \% \mathrm{RH}$ for 40 min. This spectrum is $\log _{10}\left(S_{0} / S_{1}\right)$ where $S_{0}$ and $S_{1}$ are the single beam spectra of SOA covered crystal collected before and after exposure to a flow of clean humid (89\% RH) air. The SOA is formed from ozonolysis of $\alpha$-cedrene in the chamber (experiment $\mathrm{CH} 4$, Table1). 

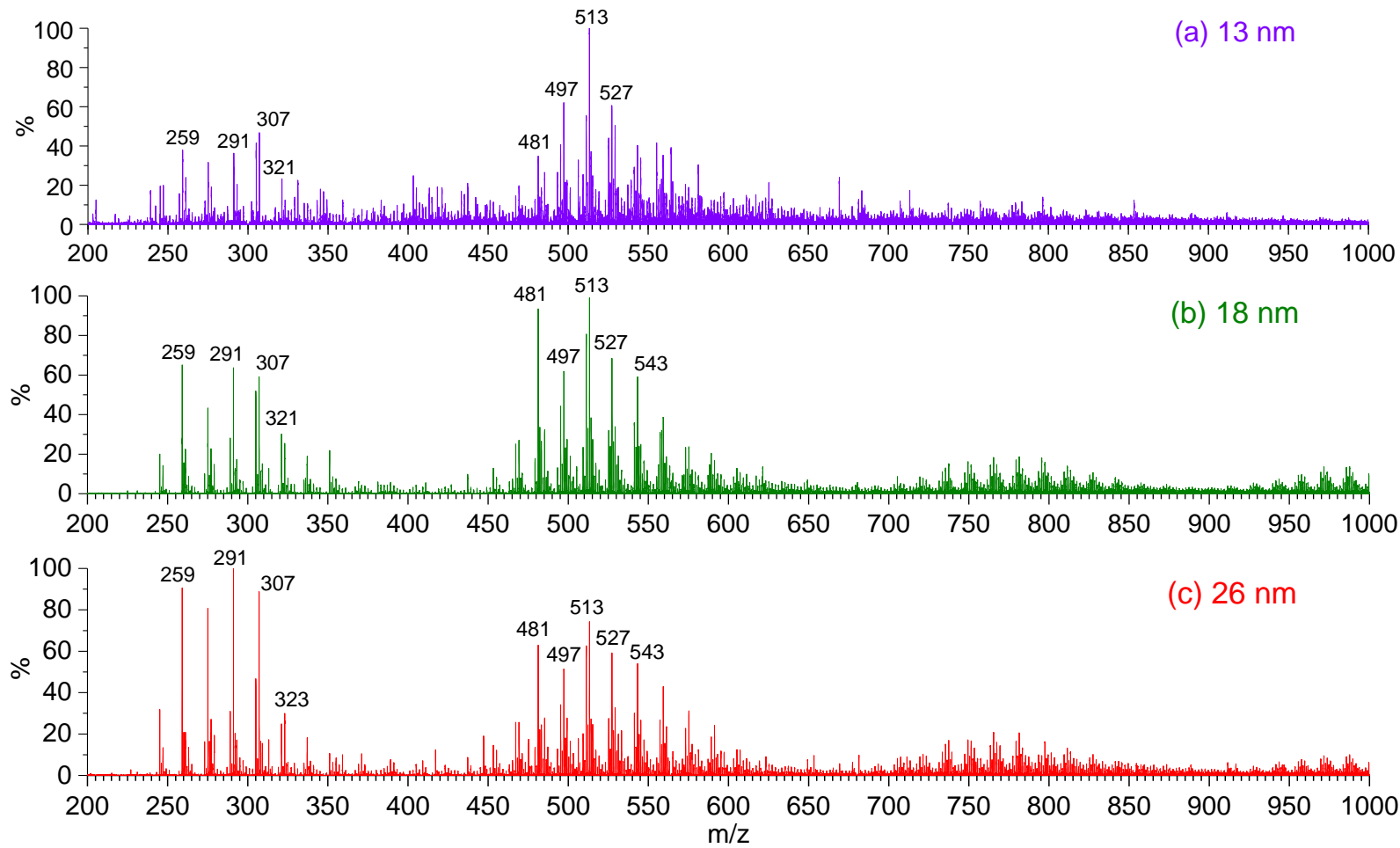

Figure S4 ESI (+) mass spectra of polydisperse SOA with geometric mean size of (a) $13 \mathrm{~nm}$, (b) $18 \mathrm{~nm}$, and (c) $26 \mathrm{~nm}$ formed from ozonolysis of $\alpha$-cedrene in the flow reactor at the same reaction time (30 s) but different $\alpha$-cedrene concentrations (Table 1, experiments FR3-FR5). The size distributions of SOA are shown in Fig. S1b. P3 and P4 products are not observed in the mass spectrum of the smallest SOA probably because the SOA has a very low mass concentration and the collected SOA mass is insufficient for the detection of these products by ESI-MS. 

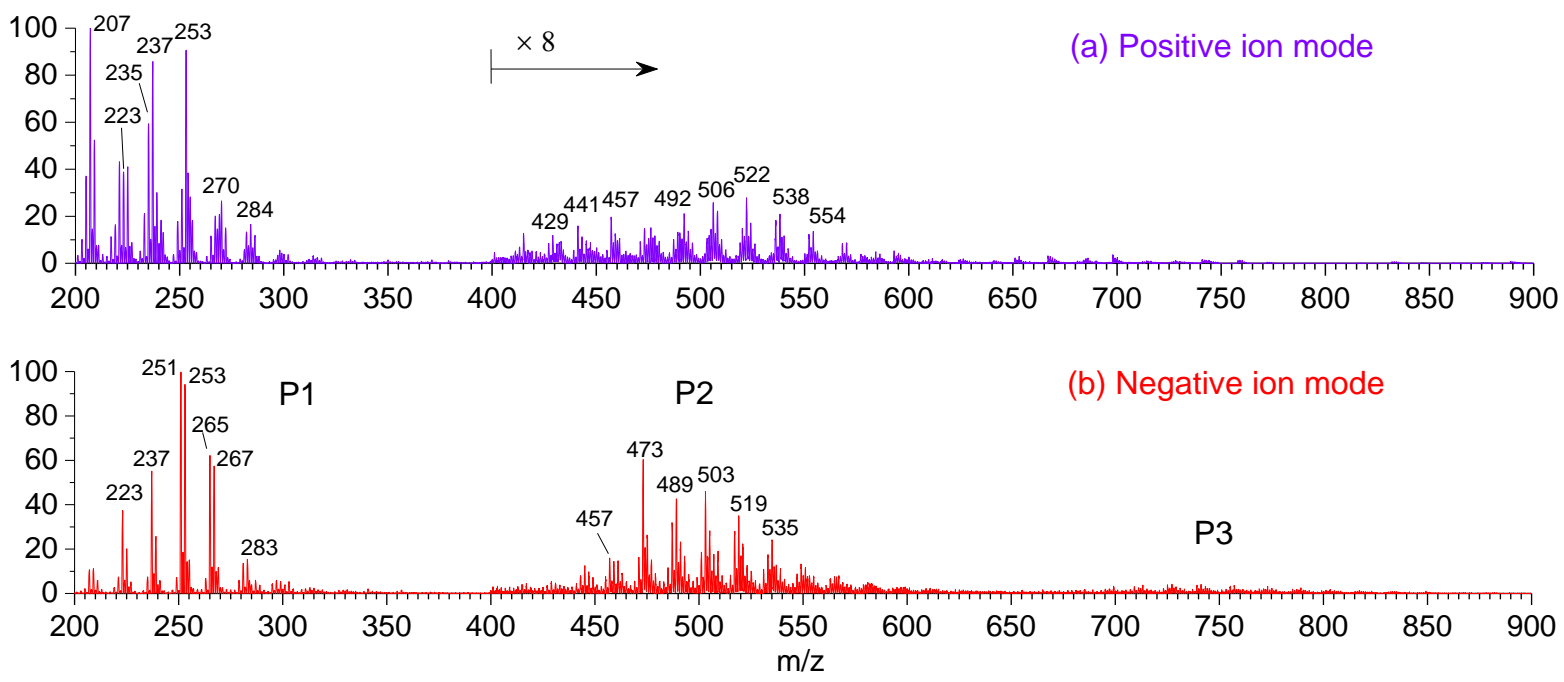

Figure S5 DART mass spectra of SOA formed from $\alpha$-cedrene ozonolysis in the flow reactor under dry conditions in (a) positive and (b) negative ion modes. Aerosol stream was heated to $160{ }^{\circ} \mathrm{C}$ before introduction into the ionization region. The signal intensity for the ions with $\mathrm{m} / \mathrm{z}$ values $>400$ in both mass spectra was enlarged by a factor of eight. 

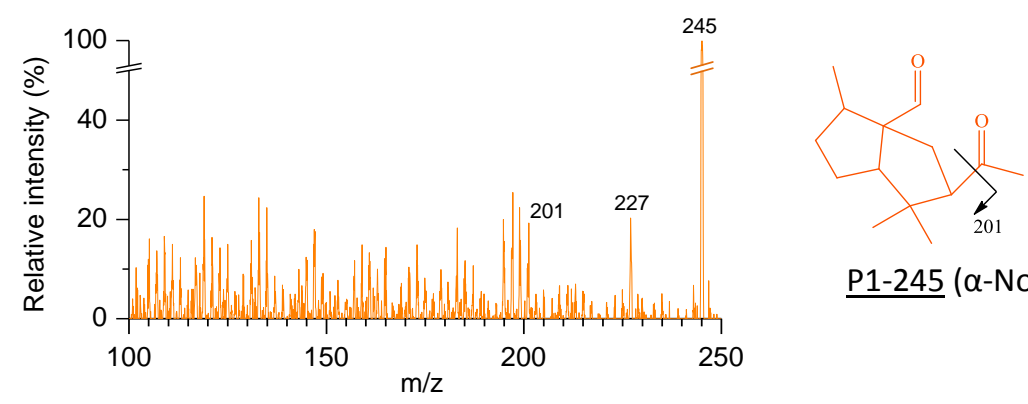

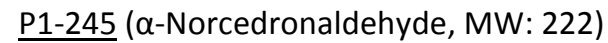
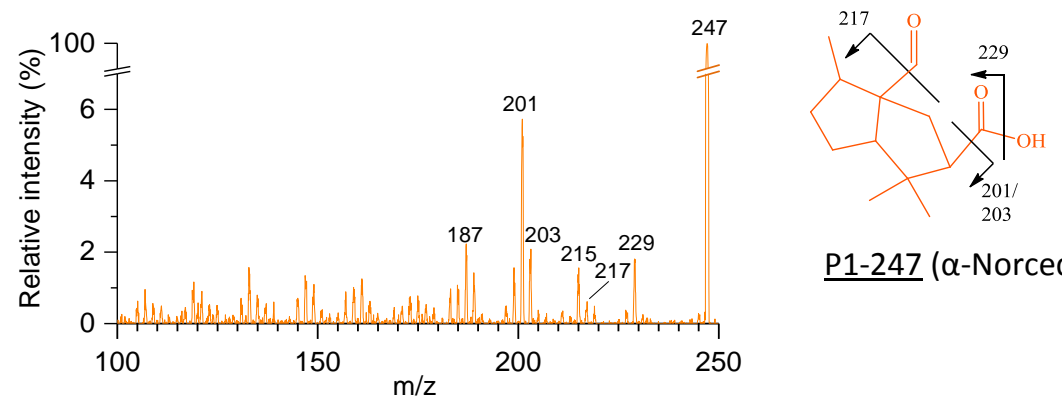

P1-247 ( $\alpha$-Norcedralic acid, MW: 224)
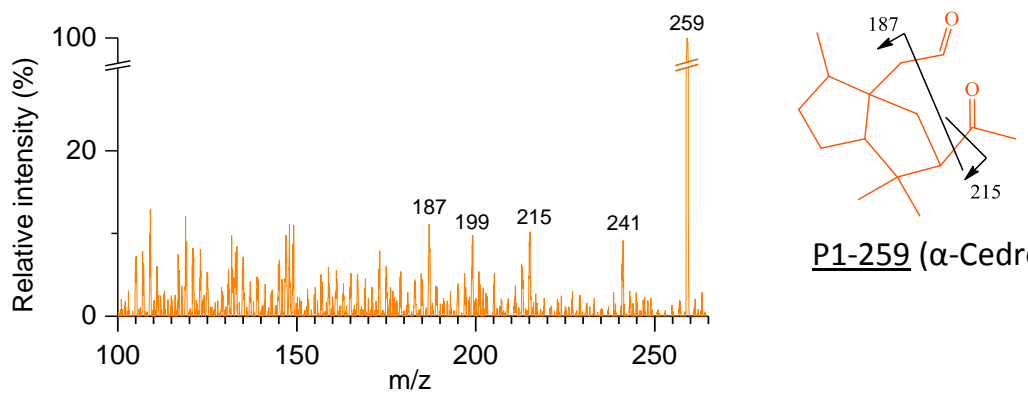

P1-259 ( $\alpha$-Cedronaldehyde, MW: 236)
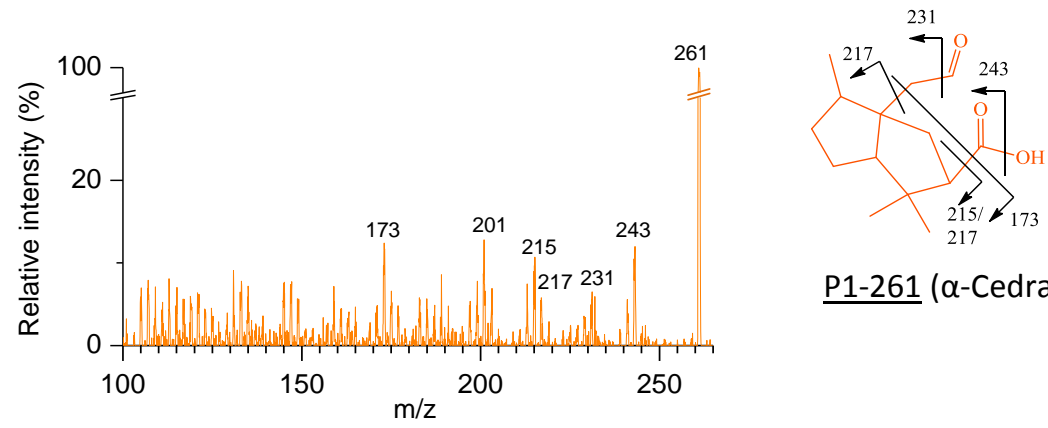

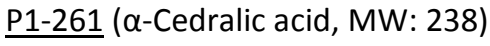

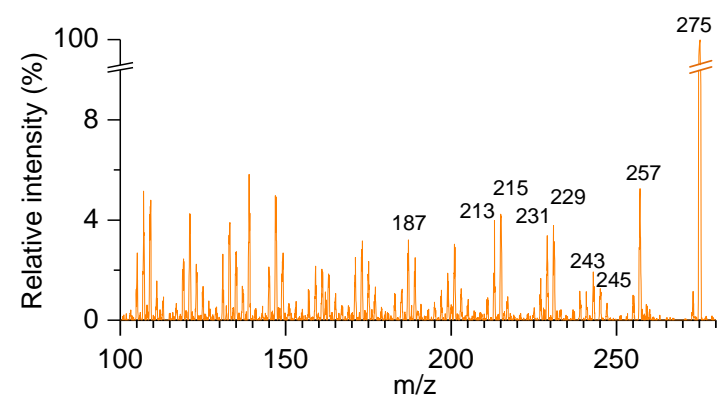

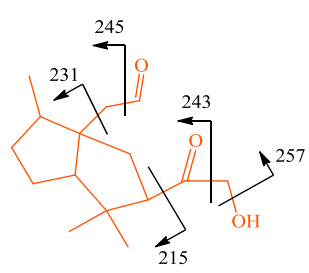

P1-275-1 (MW: 252)

(15-Hydroxy- $\alpha$ cedronaldehyde)

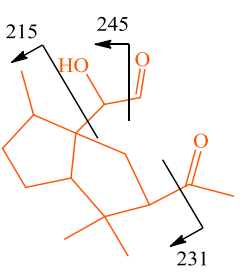

P1-275-2

(10-Hydroxy- $\alpha$ cedronaldehyde) 


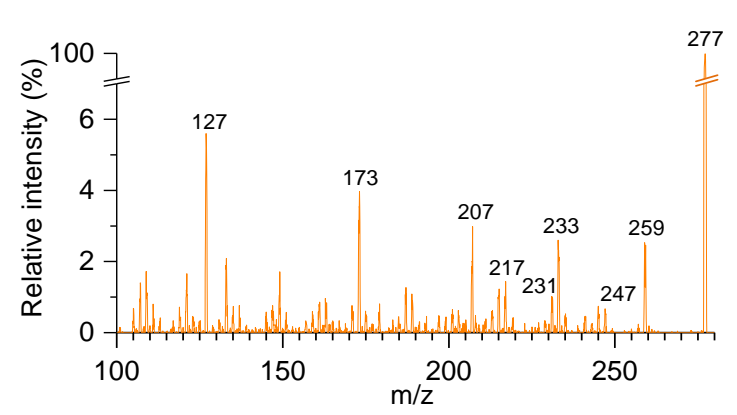

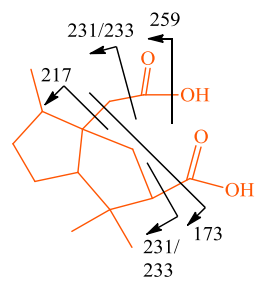

P1-277-1 (MW: 254)

( $\alpha$-Cedrinic acid)

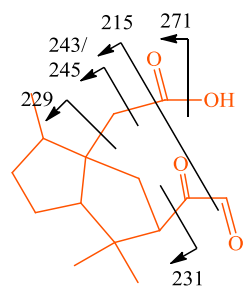

$\underline{\mathrm{P} 1-289}$ (15-Oxo- $\alpha$-cedronic acid, MW: 266)

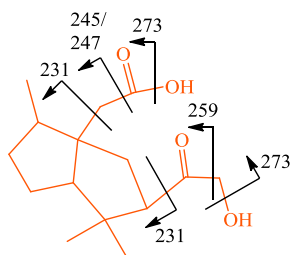

P1-291-1 (MW: 268)

(15-Hydroxy- $\alpha$ -

cedronic acid)

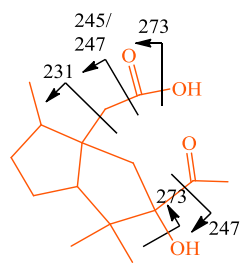

P1-291-2

(7-Hydroxy- $\alpha$ cedronic acid)

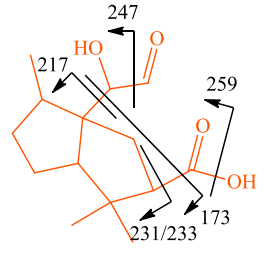

P1-277-2

(10-Hydroxy- $\alpha$-norcedralic acid)
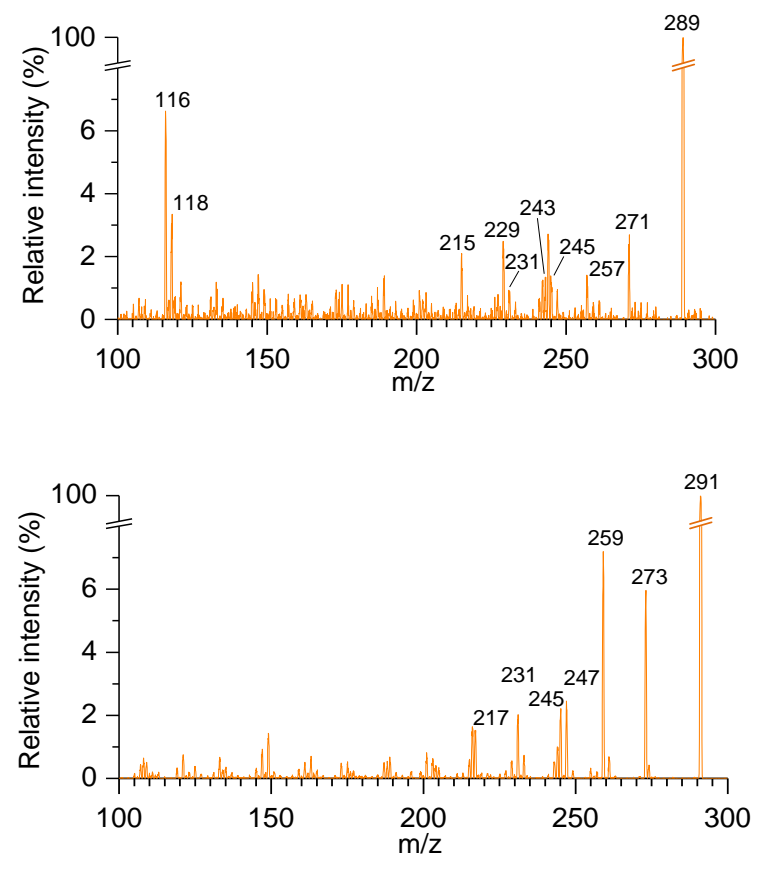

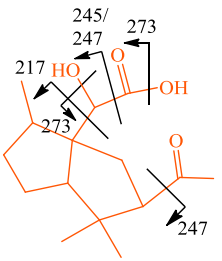

$\underline{P 1-291-3}$

(10-Hydroxy- $\alpha$ cedronic acid)

Figure S6 ESI(+)-MS ${ }^{2}$ spectra and the proposed structures of the reaction products corresponding to the $[\mathrm{M}+\mathrm{Na}]^{+}$ions of $m / z$ 245-291. Label "P1-xxx" represents a P1 product, the sodiated ion of which has a nominal mass of xxx. Labels "P1-xxx-n" $(n=1-3)$ indicate different isomeric structures for the product "P1-xxx". MW, molecular weight. 

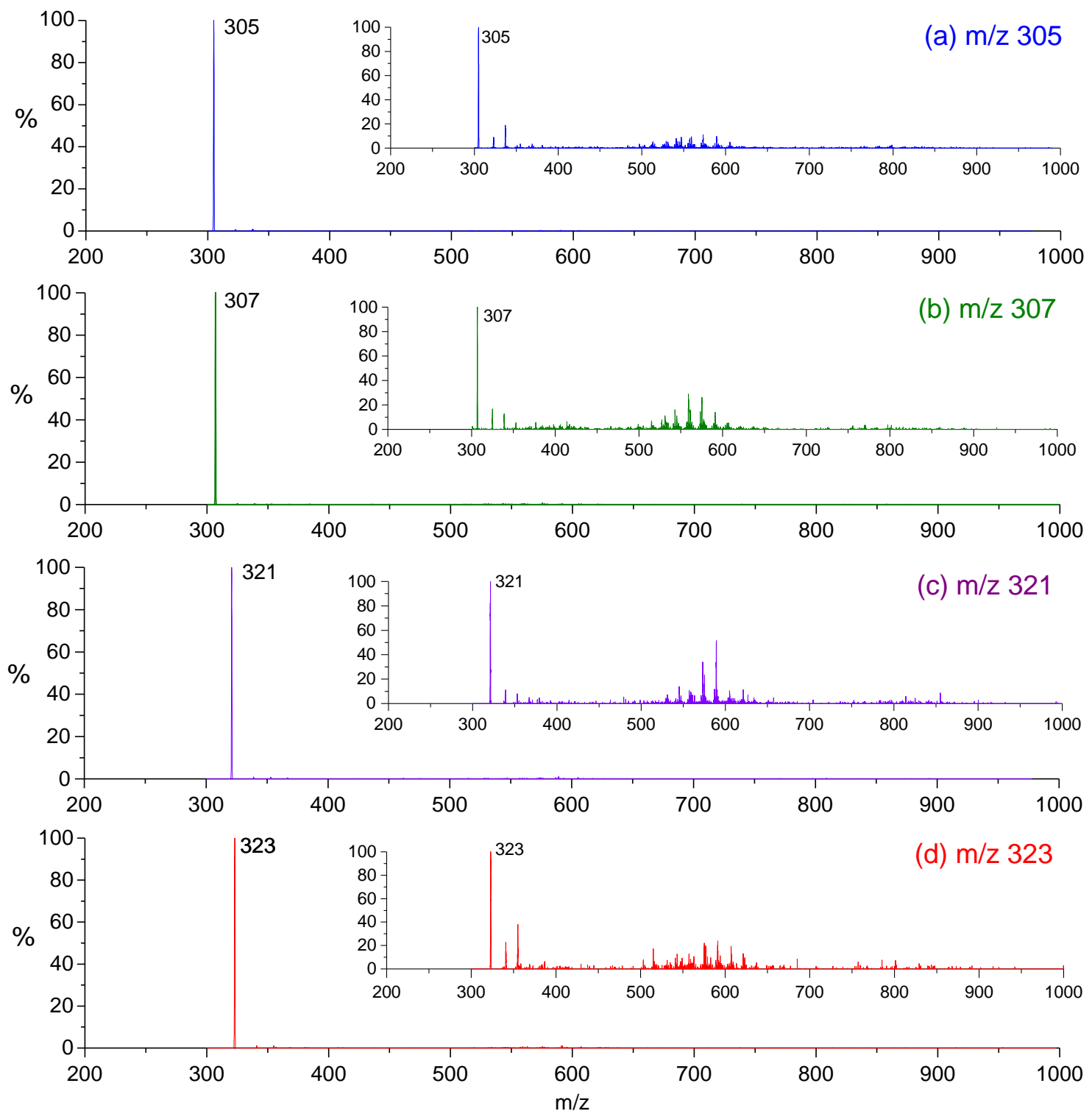

Figure S7 Parent ion spectra of sodiated ions at (a) $m / z, 305$, (b) $m / z, 307$, (c) $m / z, 321$, and (d) $m / z$. 323 at collision gas energy of $6 \mathrm{eV}$. The insets show the corresponding parent ion spectra at collision energy of $20 \mathrm{eV}$. 

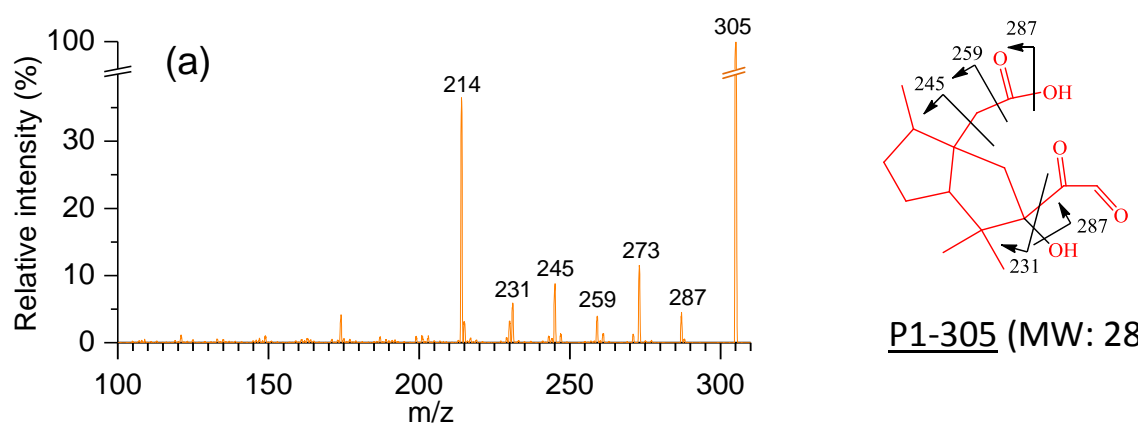

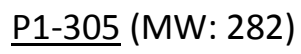

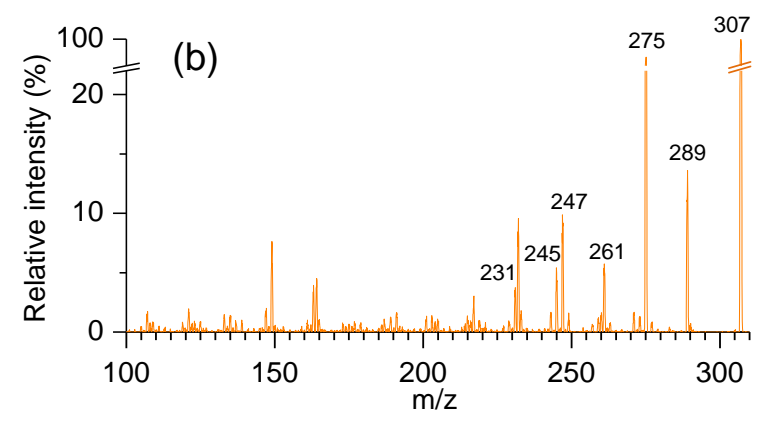

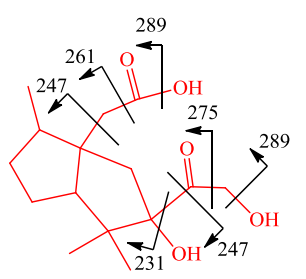

P1-307-1 (MW: 284)

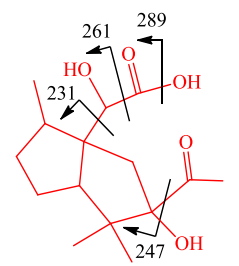

P1-307-2 (MW: 284)
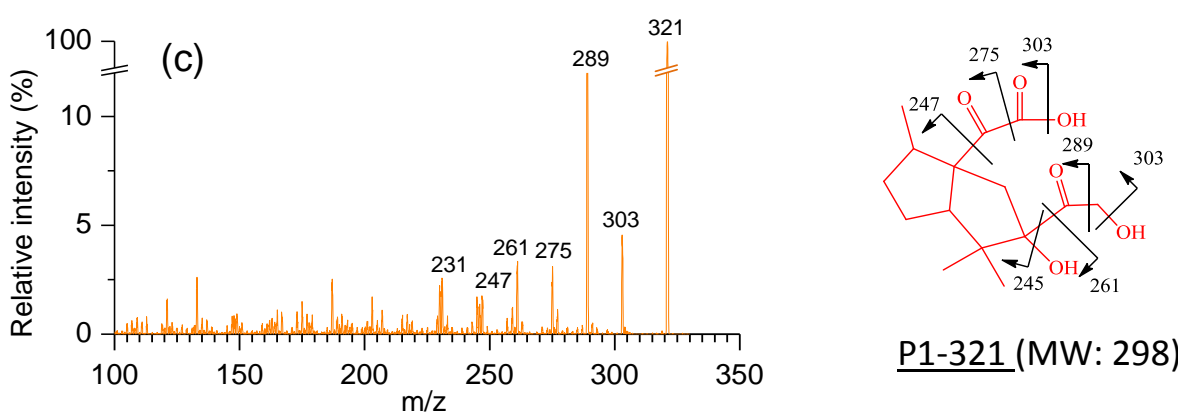

\section{P1-321 (MW: 298)}
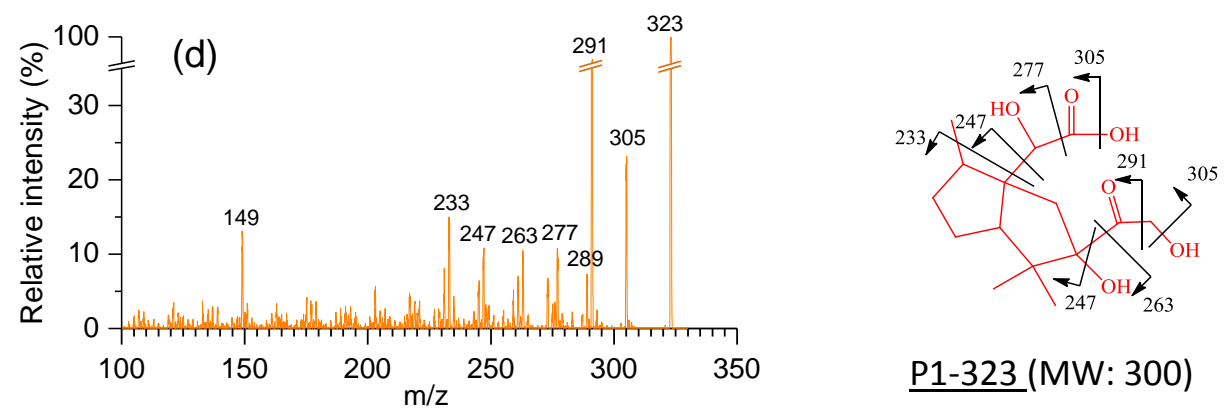

$\underline{\mathrm{P} 1-323}$ (MW: 300)

Figure S8 ESI(+)-MS ${ }^{2}$ spectra and the proposed potential structures of the newly observed reaction products corresponding to the $[\mathrm{M}+\mathrm{Na}]^{+}$ions of (a) $m / z 305$, (b) $m / z 307$, (c) $m / z 321$, and (d) $m / z$ 323. Label "P1-xxx" represents a P1 product, the sodiated ion of which has a nominal mass of $\mathrm{xxx}$. Labels "P1-xxx-1" and "P1-xxx-2" indicate different isomeric structures for the product "P1-xxx". MW, molecular weight. 


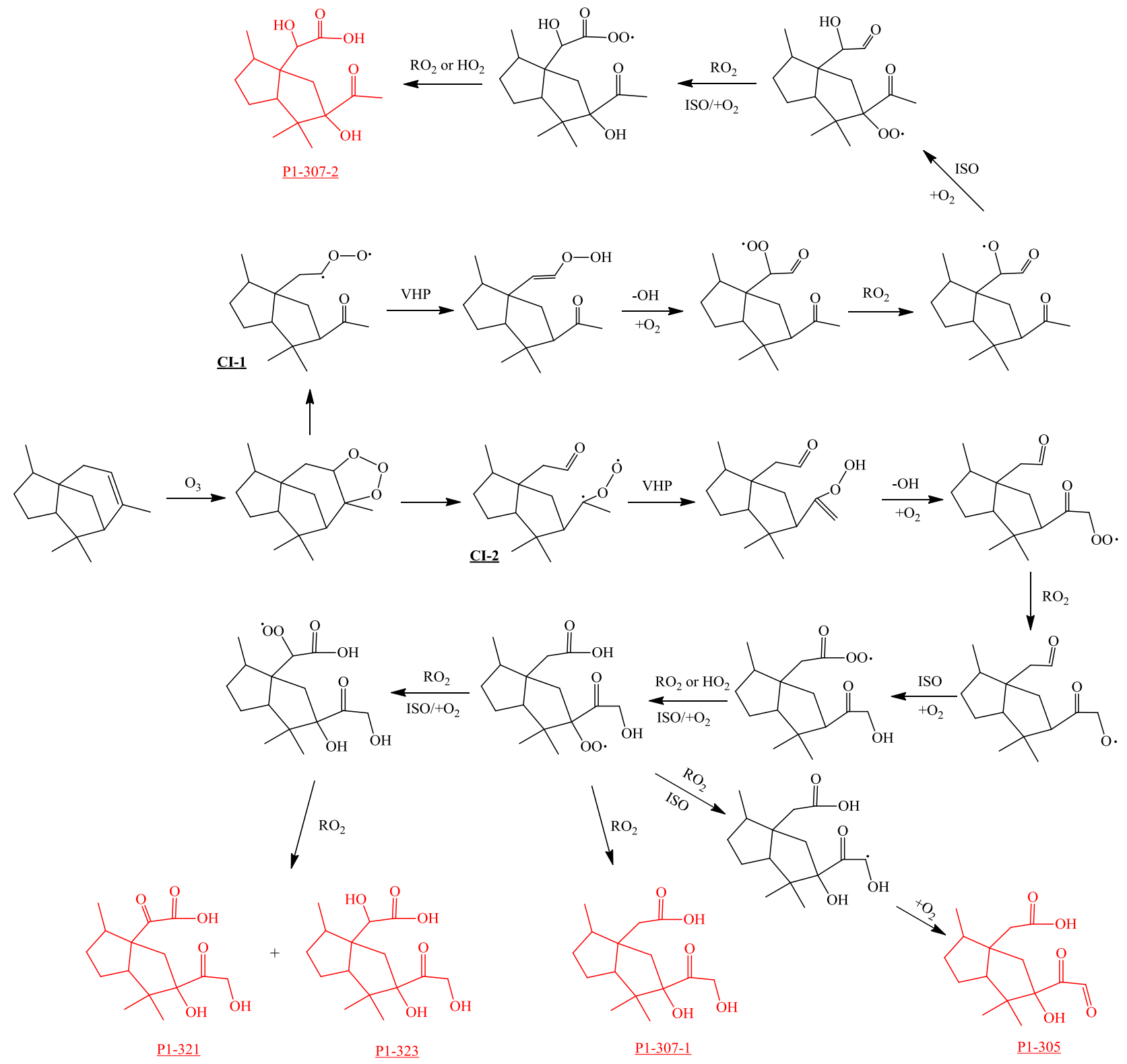

Figure S9 Possible reaction pathways leading to the formation of newly observed products (highlighted in red) during $\alpha$-cedrene ozonolysis. CI, Criegee intermediate. VHP, vinyl hydroperoxide channel. ISO, isomerization. 

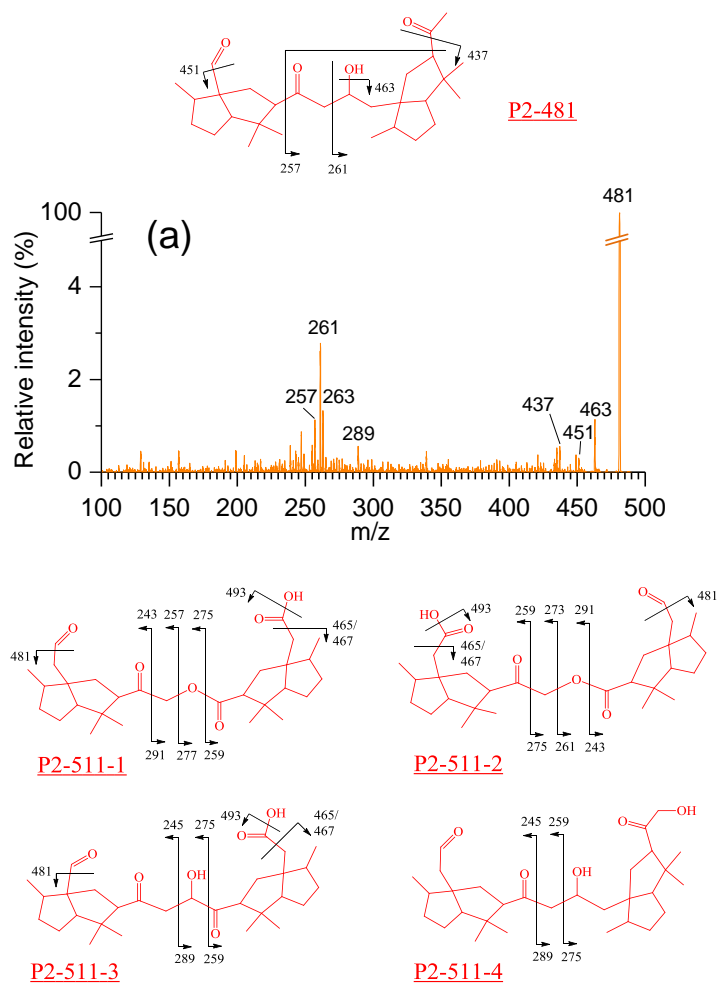

$$
\text { P2-511-3 }
$$

P2-511-4
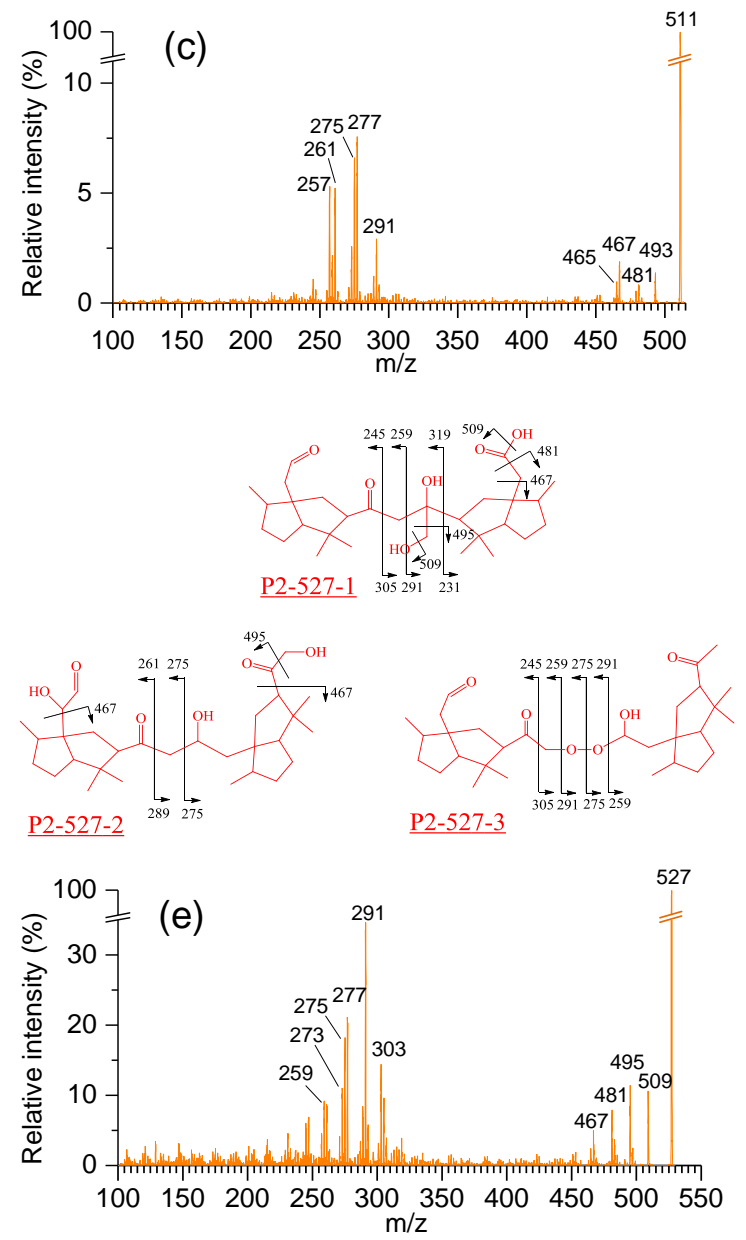
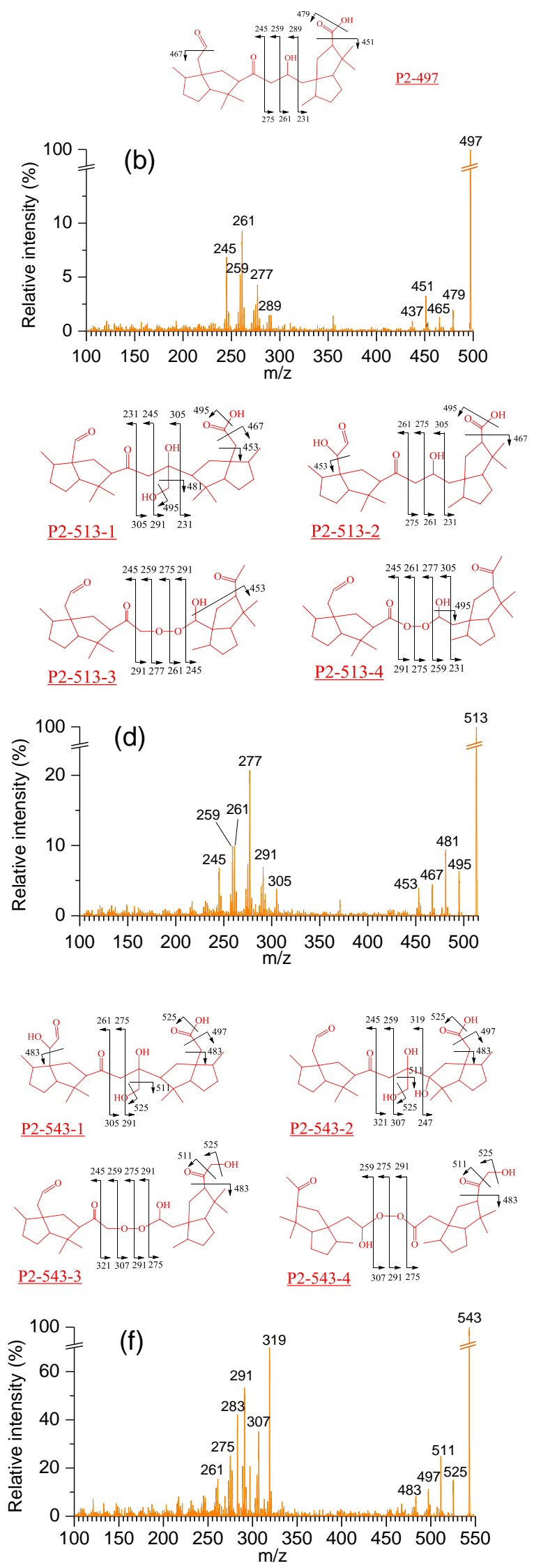
Figure S10 ESI(+)-MS ${ }^{2}$ spectra and tentatively assigned structures for the P2 products corresponding to the $[\mathrm{M}+\mathrm{Na}]^{+}$ions at (a) $m / z 481$, (b) $m / z 497$, (c) $m / z 511$, (d) $m / z 513$, (e) $m / z$ 527, and (f) $m / z 543$ formed from $\alpha$-cedrene ozonolysis. Label "P2-xxx" represents a P2 product, the sodiated ion of which has a nominal mass of Xxx. Label "P2-xxx-n" $(n=1-4)$ indicates different structures for the product "P2-xxx".

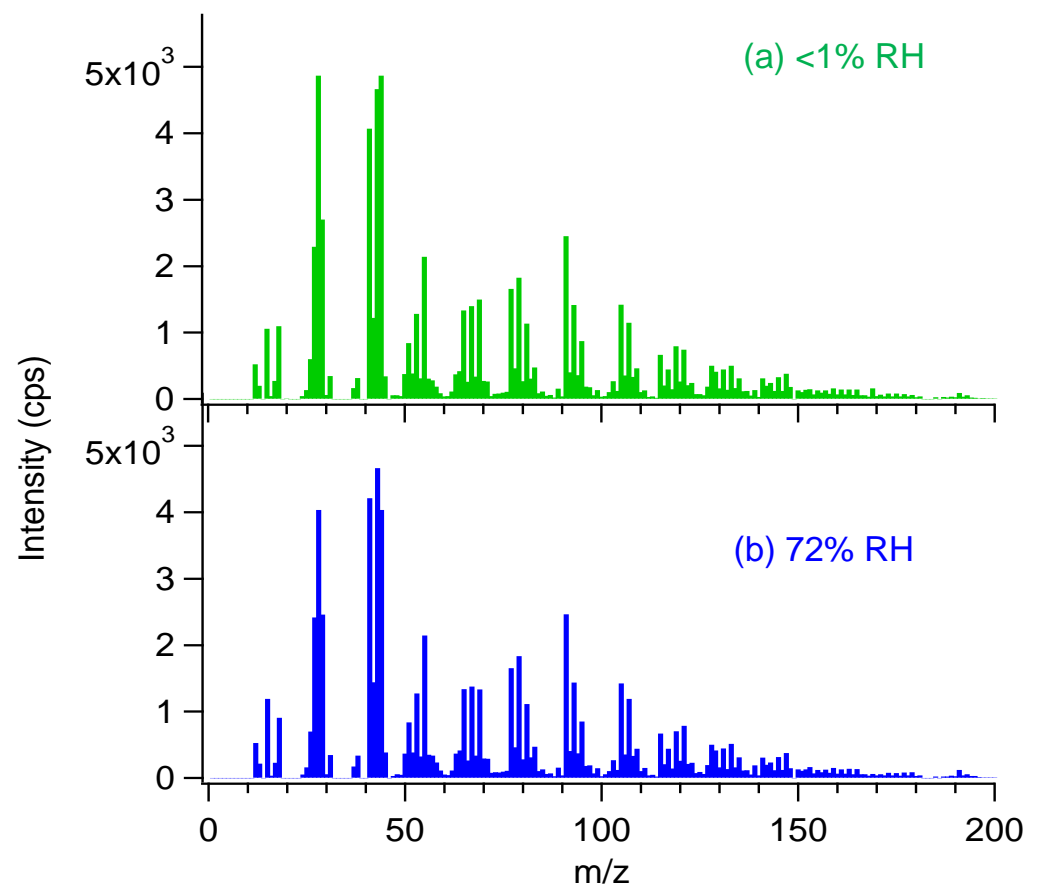

Figure S11 Aerosol mass spectra of chamber $\alpha$-cedrene SOA formed at (a) $<1 \%$ RH (green, experiment $\mathrm{CH} 1$ ) and (b) $72 \% \mathrm{RH}$ (blue, experiment $\mathrm{CH} 2$ ). 
Table S1 The saturated vapor pressures $\left(P_{\text {sat }}\right)$ of typical P1 and P2 products in $\alpha$-cedrene SOA at $295 \mathrm{~K}$ estimated using two group contribution methods, SIMPOL.1 and EVAPORATION.

\begin{tabular}{|c|c|c|c|c|c|c|c|}
\hline \multirow{2}{*}{ Products } & \multirow{2}{*}{$\begin{array}{l}\text { Molecular } \\
\text { formula }\end{array}$} & \multicolumn{2}{|c|}{$P_{\text {sat }}(\mathrm{atm})$} & \multirow{2}{*}{ Products } & \multirow{2}{*}{$\begin{array}{l}\text { Molecular } \\
\text { formula }\end{array}$} & \multicolumn{2}{|c|}{$P_{\text {sat }}(\mathrm{atm})$} \\
\hline & & SIMPOL.1 & EVAPORATION & & & SIMPOL.1 & EVAPORATION \\
\hline P1-245 & $\mathrm{C}_{14} \mathrm{H}_{22} \mathrm{O}_{2}$ & $2.8 \times 10^{-7}$ & $6.1 \times 10^{-7}$ & $\mathrm{P} 1-305$ & $\mathrm{C}_{15} \mathrm{H}_{22} \mathrm{O}_{5}$ & $1.8 \times 10^{-13}$ & $1.8 \times 10^{-11}$ \\
\hline P1-247 & $\mathrm{C}_{13} \mathrm{H}_{20} \mathrm{O}_{3}$ & $1.9 \times 10^{-9}$ & $8.4 \times 10^{-9}$ & P1-307-1 & $\mathrm{C}_{15} \mathrm{H}_{24} \mathrm{O}_{5}$ & $2.4 \times 10^{-14}$ & $1.3 \times 10^{-13}$ \\
\hline P1-259 & $\mathrm{C}_{15} \mathrm{H}_{24} \mathrm{O}_{2}$ & $1.0 \times 10^{-7}$ & $1.9 \times 10^{-7}$ & P1-307-2 & $\mathrm{C}_{15} \mathrm{H}_{24} \mathrm{O}_{5}$ & $2.4 \times 10^{-14}$ & $2.3 \times 10^{-13}$ \\
\hline P1-261 & $\mathrm{C}_{14} \mathrm{H}_{22} \mathrm{O}_{3}$ & $6.8 \times 10^{-10}$ & $2.7 \times 10^{-9}$ & $P 1-321$ & $\mathrm{C}_{15} \mathrm{H}_{22} \mathrm{O}_{6}$ & $2.8 \times 10^{-15}$ & $3.9 \times 10^{-14}$ \\
\hline P1-275-1 & $\mathrm{C}_{15} \mathrm{H}_{24} \mathrm{O}_{3}$ & $6.4 \times 10^{-10}$ & $3.9 \times 10^{-9}$ & $\mathrm{P} 1-323$ & $\mathrm{C}_{15} \mathrm{H}_{24} \mathrm{O}_{6}$ & $1.5 \times 10^{-16}$ & $8.8 \times 10^{-16}$ \\
\hline P1-275-2 & $\mathrm{C}_{15} \mathrm{H}_{24} \mathrm{O}_{3}$ & $6.4 \times 10^{-10}$ & $1.4 \times 10^{-8}$ & P2-511-1 & $\mathrm{C}_{29} \mathrm{H}_{44} \mathrm{O}_{6}$ & $1.5 \times 10^{-18}$ & $7.6 \times 10^{-18}$ \\
\hline P1-277-1 & $\mathrm{C}_{14} \mathrm{H}_{22} \mathrm{O}_{4}$ & $4.2 \times 10^{-12}$ & $2.4 \times 10^{-12}$ & P2-511-2 & $\mathrm{C}_{29} \mathrm{H}_{44} \mathrm{O}_{6}$ & $1.5 \times 10^{-18}$ & $7.6 \times 10^{-18}$ \\
\hline $\mathrm{P} 1-277-2$ & $\mathrm{C}_{14} \mathrm{H}_{22} \mathrm{O}_{4}$ & $4.2 \times 10^{-12}$ & $5.2 \times 10^{-11}$ & P2-513-3 & $\mathrm{C}_{29} \mathrm{H}_{46} \mathrm{O}_{6}$ & $6.9 \times 10^{-17}$ & $6.7 \times 10^{-17}$ \\
\hline P1-289 & $\mathrm{C}_{15} \mathrm{H}_{22} \mathrm{O}_{4}$ & $2.9 \times 10^{-11}$ & $4.1 \times 10^{-10}$ & P2-513-4 & $\mathrm{C}_{29} \mathrm{H}_{46} \mathrm{O}_{6}$ & $6.9 \times 10^{-17}$ & $5.2 \times 10^{-17}$ \\
\hline P1-291-1 & $\mathrm{C}_{15} \mathrm{H}_{24} \mathrm{O}_{4}$ & $3.9 \times 10^{-12}$ & $3.9 \times 10^{-12}$ & P2-527-3 & $\mathrm{C}_{30} \mathrm{H}_{48} \mathrm{O}_{6}$ & $9.4 \times 10^{-18}$ & $2.1 \times 10^{-17}$ \\
\hline P1-291-2 & $\mathrm{C}_{15} \mathrm{H}_{24} \mathrm{O}_{4}$ & $3.9 \times 10^{-12}$ & $3.1 \times 10^{-11}$ & P2-543-3 & $\mathrm{C}_{30} \mathrm{H}_{48} \mathrm{O}_{7}$ & $5.8 \times 10^{-20}$ & $1.6 \times 10^{-19}$ \\
\hline P1-291-3 & $\mathrm{C}_{15} \mathrm{H}_{24} \mathrm{O}_{4}$ & $3.9 \times 10^{-12}$ & $6.1 \times 10^{-12}$ & P2-543-4 & $\mathrm{C}_{30} \mathrm{H}_{48} \mathrm{O}_{7}$ & $1.5 \times 10^{-19}$ & $1.3 \times 10^{-19}$ \\
\hline
\end{tabular}

Note: The products highlighted in red have vapor pressures lower than the suggested nucleation threshold, i.e., $\sim 10^{-13} \mathrm{~atm}$. 


\section{Reference:}

Claeys, M., Iinuma, Y., Szmigielski, R., Surratt, J. D., Blockhuys, F., Van Alsenoy, C., Boge, O., Sierau, B., Gomez-Gonzalez, Y., Vermeylen, R., Van der Veken, P., Shahgholi, M., Chan, A. W. H., Herrmann, H., Seinfeld, J. H., and Maenhaut, W.: Terpenylic Acid and Related Compounds from the Oxidation of alpha-Pinene: Implications for New Particle Formation and Growth above Forests, Environ. Sci. Technol., 43, 6976-6982, 2009.

DePalma, J. W., Horan, A. J., Hall, W. A., and Johnston, M. V.: Thermodynamics of oligomer formation: implications for secondary organic aerosol formation and reactivity, Phys. Chem. Chem. Phys., 15, 6935-6944, 2013.

Gao, Y. Q., Hall, W. A., and Johnston, M. V.: Molecular Composition of Monoterpene Secondary Organic Aerosol at Low Mass Loading, Environ. Sci. Technol., 44, 7897-7902, doi:10.1021/Es101861k, 2010.

Hall, W. A., and Johnston, M. V.: Oligomer Formation Pathways in Secondary Organic Aerosol from MS and MS/MS Measurements with High Mass Accuracy and Resolving Power, J. Am. Soc. Mass Spectrom., 23, 1097-1108, 2012.

Hallquist, M., Wenger, J. C., Baltensperger, U., Rudich, Y., Simpson, D., Claeys, M., Dommen, J., Donahue, N. M., George, C., Goldstein, A. H., Hamilton, J. F., Herrmann, H., Hoffmann, T., Iinuma, Y., Jang, M., Jenkin, M. E., Jimenez, J. L., Kiendler-Scharr, A., Maenhaut, W., McFiggans, G., Mentel, T. F., Monod, A., Prevot, A. S. H., Seinfeld, J. H., Surratt, J. D., Szmigielski, R., and Wildt, J.: The formation, properties and impact of secondary organic aerosol: current and emerging issues, Atmos. Chem. Phys., 9, 51555236, 2009.

Heaton, K. J., Sleighter, R. L., Hatcher, P. G., Hall, W. A., and Johnston, M. V.: Composition Domains in Monoterpene Secondary Organic Aerosol, Environ. Sci. Technol., 43, 7797$7802,2009$.

Hoffmann, T., Bandur, R., Marggraf, U., and Linscheid, M.: Molecular composition of organic aerosols formed in the alpha-pinene/O-3 reaction: Implications for new particle formation processes, J. Geophys. Res., 103, 25569-25578, 1998.

Kristensen, K., Enggrob, K. L., King, S. M., Worton, D. R., Platt, S. M., Mortensen, R., Rosenoern, T., Surratt, J. D., Bilde, M., Goldstein, A. H., and Glasius, M.: Formation and occurrence of dimer esters of pinene oxidation products in atmospheric aerosols, Atmos. Chem. Phys., 13, 3763-3776, 2013.

Kristensen, K., Cui, T., Zhang, H., Gold, A., Glasius, M., and Surratt, J. D.: Dimers in alphapinene secondary organic aerosol: effect of hydroxyl radical, ozone, relative humidity and aerosol acidity, Atmos. Chem. Phys., 14, 4201-4218, 2014.

Muller, L., Reinnig, M. C., Warnke, J., and Hoffmann, T.: Unambiguous identification of esters as oligomers in secondary organic aerosol formed from cyclohexene and cyclohexene/alpha-pinene ozonolysis, Atmos. Chem. Phys., 8, 1423-1433, 2008.

Muller, L., Reinnig, M. C., Hayen, H., and Hoffmann, T.: Characterization of oligomeric compounds in secondary organic aerosol using liquid chromatography coupled to electrospray ionization Fourier transform ion cyclotron resonance mass spectrometry, Rapid Commun. Mass Spectrom., 23, 971-979, 2009.

Reinnig, M. C., Warnke, J., and Hoffmann, T.: Identification of organic hydroperoxides and hydroperoxy acids in secondary organic aerosol formed during the ozonolysis of different monoterpenes and sesquiterpenes by on-line analysis using atmospheric pressure 
chemical ionization ion trap mass spectrometry, Rapid Commun. Mass Spectrom., 23, 1735-1741, doi:10.1002/Rcm.4065, 2009.

Sloth, M., Bilde, M., and Mikkelsen, K. V.: Interaction energies between aerosol precursors formed in the photo-oxidation of alpha-pinene, Mol. Phys., 102, 2361-2368, doi:10.1080/00268970412331317805, 2004.

Tolocka, M. P., Jang, M., Ginter, J. M., Cox, F. J., Kamens, R. M., and Johnston, M. V.: Formation of oligomers in secondary organic aerosol, Environ. Sci. Technol., 38, 14281434, 2004.

Witkowski, B., and Gierczak, T.: Early stage composition of SOA produced by alphapinene/ozone reaction: alpha-Acyloxyhydroperoxy aldehydes and acidic dimers, Atmos. Environ., 95, 59-70, 2014.

Yasmeen, F., Vermeylen, R., Szmigielski, R., Iinuma, Y., Boge, O., Herrmann, H., Maenhaut, W., and Claeys, M.: Terpenylic acid and related compounds: precursors for dimers in secondary organic aerosol from the ozonolysis of alpha- and beta-pinene, Atmos. Chem. Phys., 10, 9383-9392, 2010. 